\title{
Uncharted territory: Hippocratic ethics and health systems
}

I $\mathrm{n}$ the wake of the Supreme Court decision on the Chaoulli case, the CMA will be advising on the relationship between the public and private sectors in the delivery and funding of health care. It is crucial that Canadian doctors recognize that this issue is deeply rooted in some unresolved issues of physician ethics.

Doctors make their living from suffering, pain, fear and hope. Precisely because of this, the public profession of physicians' commitment to the welfare of the patient has been a cardinal feature of the Hippocratic tradition. ${ }^{1}$ This commitment had been described as self-effacing; it is now understood to be altruistic. The ethic developed when payment was direct: there was no system of diagnostic and therapeutic services and no teams of care providers. By the I8oos the notion of the profession was conceived, with its core elements of competence, commitment to the patient's welfare, and medicine as a public trust. If medicine is to remain a profession and not a business, all three elements of professionalism must be included in the deliberations of the CMA.

The practice of medicine has changed significantly from its Hippocratic roots. The requirement of competence endures. However, the doctor-patient relationship has changed, with more knowledgeable and demanding patients and the formal requirements of informed consent and respect for patient autonomy. The patient's welfare is often complex and contested because medicine almost always has something else that could be done. The obligation of physicians to recommend interventions based on evidence of benefit and harm is challenged by patients who have the expectations of a consumer. When more diagnostics and intervention, whether indicated or not, make the health care "consumer" happy and benefit the physician personally, the fiduciary challenge becomes very real. The organization and delivery of care is now in complex systems provided by multiprofessional teams. Funding has moved to a variety of public and private insurance schemes characterized by shared risk, fixed resources and insulation of both doctors and patients from costs.

The first code in the CMA Code of Ethics confirms the fundamental commitment: "Consider first the well-being of the patient." However, the physician is no longer the provider of f all the resources needed. So, the Code also recognizes "... the responsibility of physicians to promote equitable access to health care resources" (no. 43) and to "Use health care resources prudently" (no. 44). Doctors are frustrated and at times experience a kind of moral anguish when they feel compromised in their duty to individual patients because of system limits and inefficiencies. There is no robust body of ethical reflection that assists doctors in balancing these new and conflicting obligations. So, our profession needs to do some serious work on the meaning of "equitable access to health care resources" and "the prudent use of resources" before it can give credible advice regarding the relationship between the public and private sectors of health care.

The profession needs first to be honest about the conflicts of interest inherent in recommendations regarding the funding and delivery of health care. Doctors' interests can conflict with patients' interests; personal remuneration can conflict with the duty to provide effective, prudent care, and the needs of one patient can threaten the care of others. The interests of some practitioners could be advanced by a private, parallel tier, but those of others, such as practitioners in geriatrics, palliative care and family medicine, especially in rural and remote areas, could be severely compromised.

Accepting medicine as a public trust requires a careful consideration of how changes to systems affect both access to and quality of care. The profession must base its support for changes on a commitment to best evidence - a fundamental ethical obligation of medicine. That evidence indicates that wait times in the public sector increase as a consequence of private parallel systems. ${ }^{2,3}$ How ought that evidence be taken into account? What evidence is there, from other countries that have increased private funding of care, for the consequences of this change on physician resources for the public system?

Should the profession recommit to the Hippocratic ideal of undivided loyalty to individual patients, or reconceive its role as one of balancing commitments to the well-being of patients with just stewardship of health care resources? These questions must be addressed by Canadian doctors before any meaningful advice can be given to others. Will the business of modern medicine prevail over the moral core? A fundamental question of physician ethics indeed.

\section{Nuala Kenny \\ Department of Bioethics \\ Dalhousie University \\ Halifax, NS}

This article has been peer-reviewed.

\section{REFERENCES}

I. Jonsen AR. A short history of medical ethics. New York: Oxford University Press; 2000.

2. Barer M. Experts and evidence: new challenges in knowledge translation. In: Flood C, Roach K, Sossin L, editors. Access to care access to justice: the legal debate over private health insurance in Canada. Toronto: University of Toronto Press; 2005. p. 216-9.

3. Tuohy C. How does private finance affect public health care systems? Marshalling the evidence from OECD nations, 2004. J Health Polit Policy Law 2004;3:359-96. 